\title{
Sudden Anterior Tibial Tubercle Avulsion Fracture
}

\author{
Daniel Godoy-Monzon, $M D^{1,2}$, Jose Manuel Pascual-Espinosa, $M D^{2}$ \\ ${ }^{1}$ Orthopedic and Traumatology Service, Hip Unit, Hospital Italiano de Buenos Aires, Argentina \\ ${ }^{2}$ Orthopedic and Traumatology Service, Hospital Santa Maria del Puerto, Spain
}

\begin{abstract}
Acute avulsion fractures of the Anterior Tibial Tubercle are uncommon and affect the growth physis. We present a preadolescent boy with sudden pain, and locked knee, and review the diagnostic systematic and treatment.
\end{abstract}

\section{Introduction}

The incidence for acute avulsion fractures of the Anterior Tibial Tubercle (ATT) is very uncommon and the extent of the lesion affecting the growth physis is difficult to measure. The presentation rate is about 0.4 to $2.7 \%$, affecting pre adolescents around 15 years [1,2].

The mechanisms related to the injury are extreme passive flexion of the knee versus a contracted quadriceps jumping and falling or a violent contraction of the cuadriceps with a fixed tibia kicking [3].

\section{Case}

A 13-year-old boy arrived to our Emergency Unit directly from a football court, presenting complete limitation to walk, swollen and painful left knee. The patient do not suffer direct trauma, experimented a sudden pain during running after a ball that make him limb. After a few minutes the pain was extreme and the knee locked.

He had 3 years before a story of bilateral pain on the knee diagnosed as Osgood Slater and treated with analgesics, and sport suspension for 2 months, after that he returned to normal activities without limitations.

Initial radiographic evaluation included bilateral anteroposterior and lateral view of the knees. And showed an avulsion of the anterior tibial tubercle with compromise of the tibial growth physis. In order to identify the extension of the growing plate injury a MRI was performed (Figures 1 and Figure 2). Classified as type 3B of the modified Osgood Slater Classification (Figure 3).

The patient was admitted and surgery was done on same day after informed consent authorization by the parents. On a supine position with tourniquet and cuadriceps extension to achieve reduction of the extensor mechanism, we performed a medial Para patellar approach with extraarticular reduction of the fragments, reduction was achieved with a clamp and maintained with $\mathrm{k}$ wires to definitive fixation with

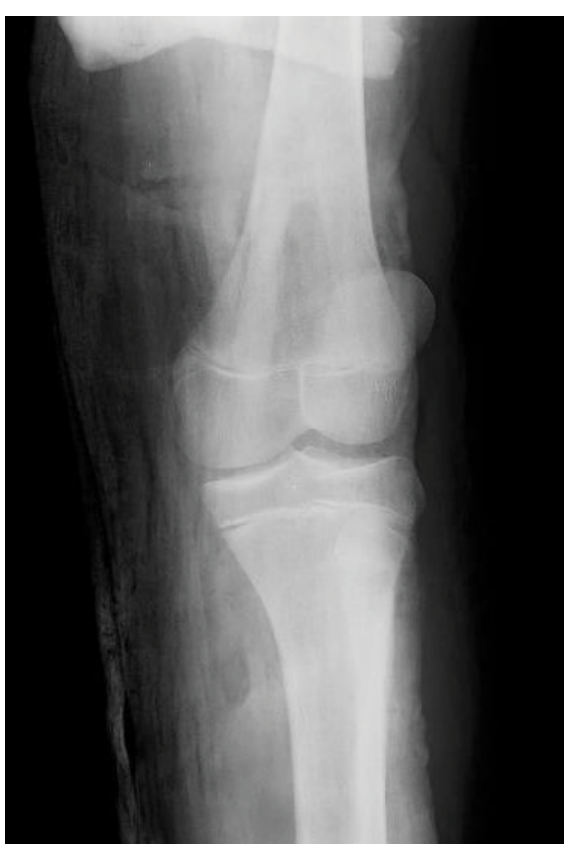

Figure 1: Anteroposterior view of the knee.

two $4.5 \mathrm{~mm}$ partial threated cannulated screw under radioscopic control to confirm adequate physis articular fragments alinement and not invade it. Postoperative pain management with oral analgesics and antibiotic for 24 hours (Figure 4, Figure 5 and Figure 6).

*Corresponding author: Daniel Godoy-Monzon, MD, Orthopedic and Traumatology Service, Hospital Italiano de Buenos Aires, Buenos Aires, Argentina

Accepted: December 29, 2020

Published online: December 31, 2020

Citation: D Godoy-Monzon, JM Pascual-Espinosa (2020) Sudden Anterior Tibial Tubercle Avulsion Fracture. Adv Tech Musculoskelet Surg 4(2):55-58 


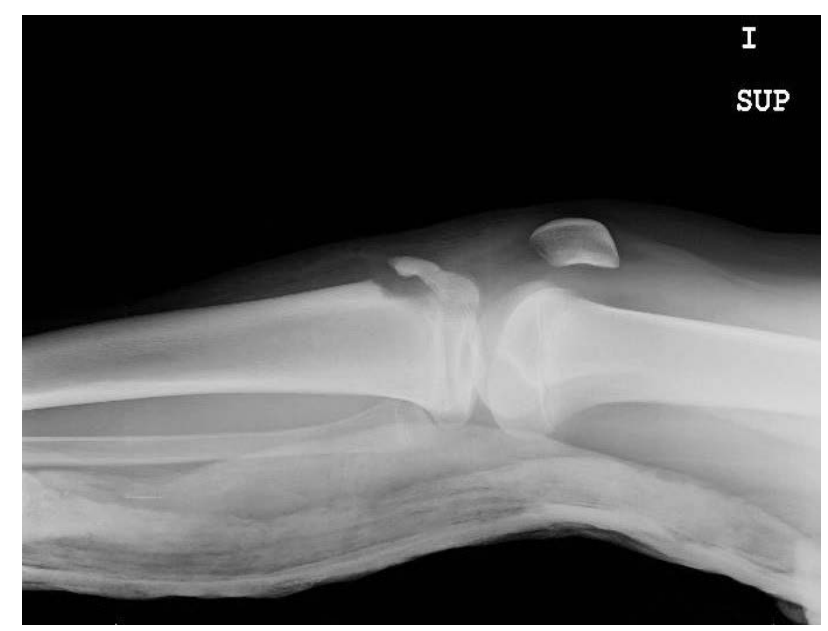

Figure 2: Lateral view of the knee.
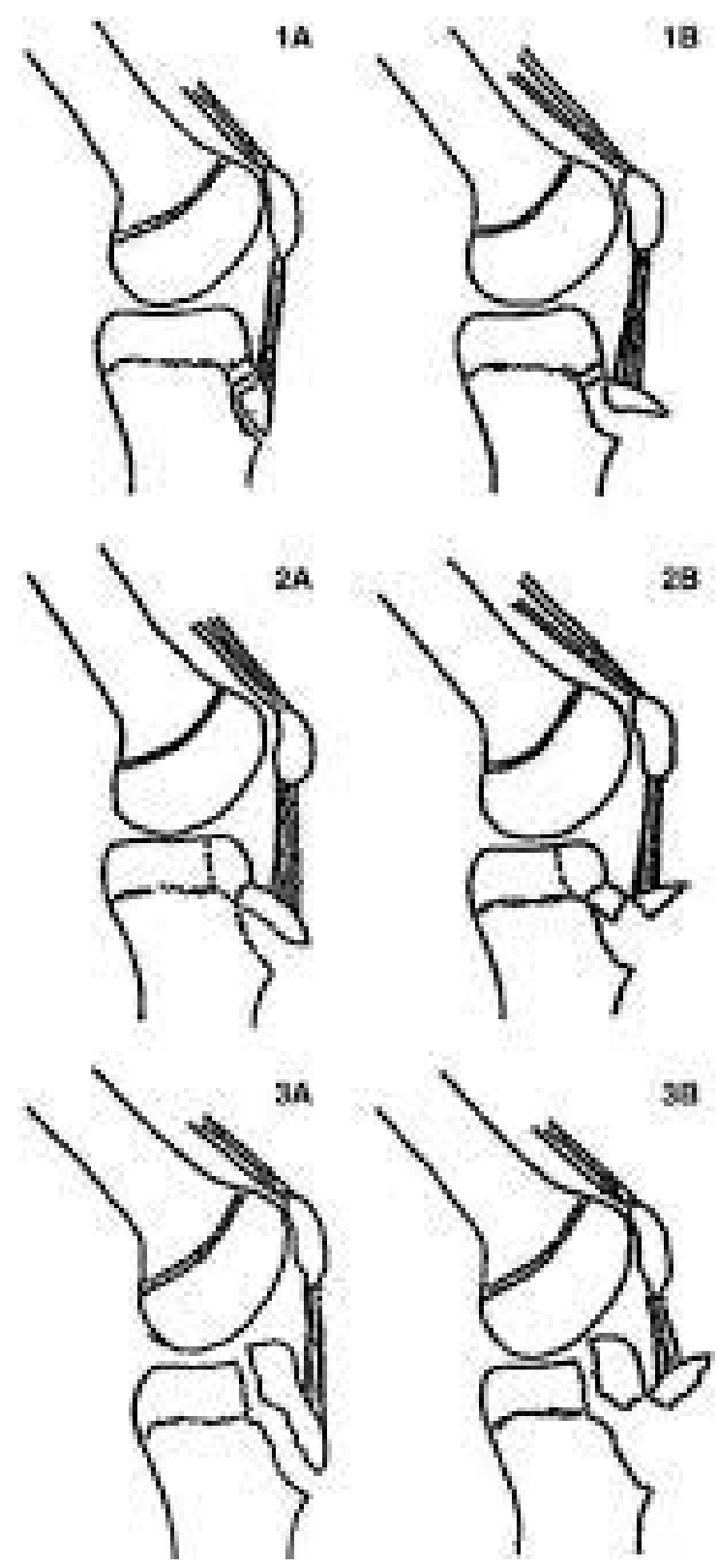

Figure 3: Osdens classification.

18

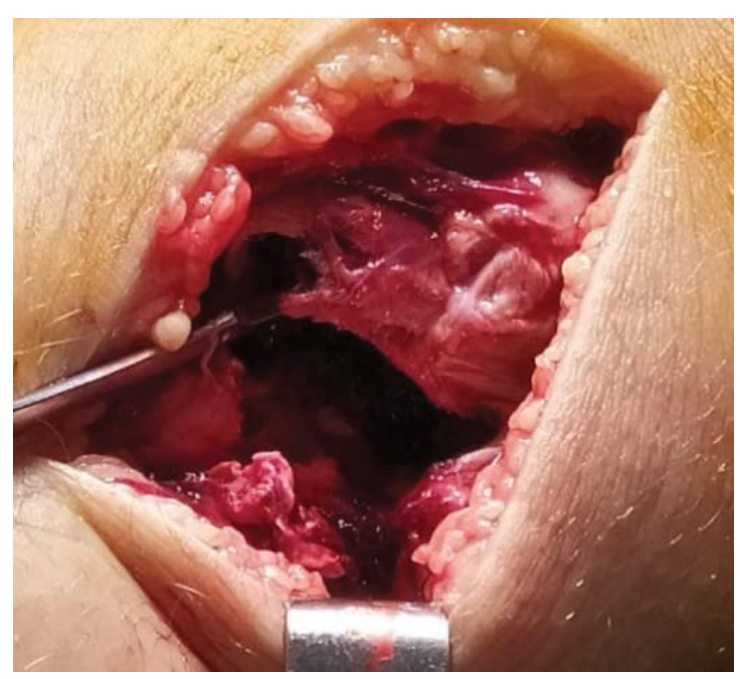

Figure 4: Intraoperative fracture view.
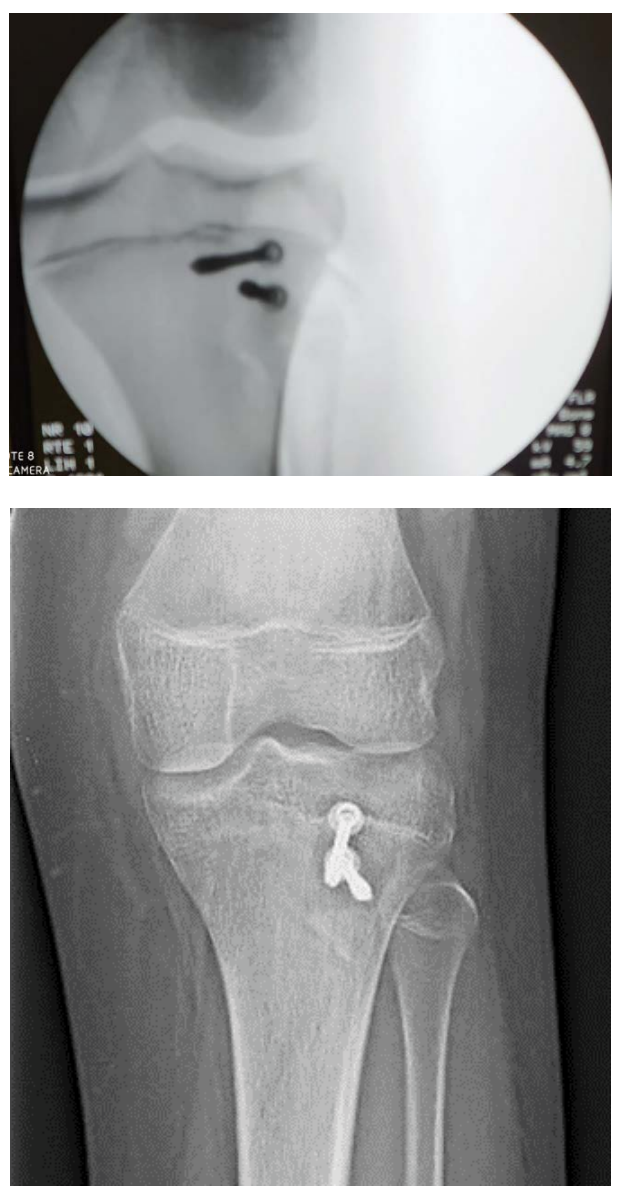

Figure 5: Anteroposterior view intraop and last follow up.

The patient was discharged using a cast and crutches non weight bearing with no complications at day 2 of admission. Controls at 3 weeks showed a painless knee, with good passive motion range, at 2 months follow up X-rays showed fracture healing and patient start with weight bearing and use of bracing during physical therapy, and specific exercises of muscle control. At 6 months the patients was allowed to re- 

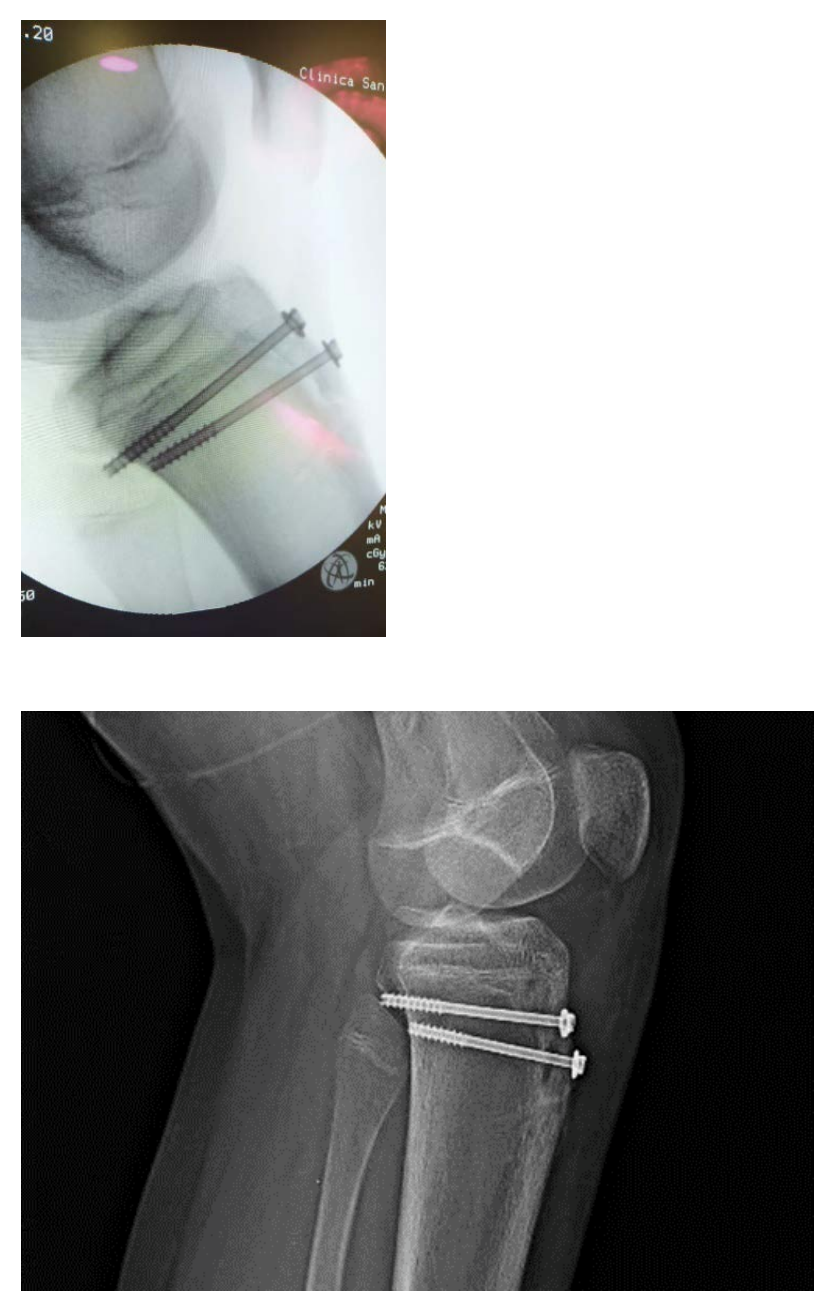

Figure 6: Lateral view intraop and last follow up.

turn to sports activities with full range of motion and pain free. The patient was informed the option to remove the internal fixation in case of discomfort.

\section{Discussion}

There is agreement in many reports that previous Osgood Slater is a main predisposing factor and reflects a repetitive stress suffered during the ossification of the Fibrocartilage of the ATT and its connection to tibia plateau physis. The tibia tuberosity develops from a secondary ossification nucleus and as the tibia plateau physis tends to close in a posterior to anterior fashion. The typical presentation involves the anterior part and or lateral part of the physis [2-4].

The most popular classification is Ogden which adds subtypes A and B to the original Watson Jones classification [5].

As radiographic evaluation is not enough to have a clear idea of the damage and MRI can give a full information of the growing plate injury and the fracture pattern, concomitant ligament or meniscus lesions, in order to achive a correct diagnosis, and treatment strategy.

The mechanisms of injury described involve the extension mechanism contraction and traction on the ATT Fibrocartilage, tearing the periosteum and transferring damage to the growth plate [3].
Some reports refer the lesion to semi-professional or high demand sportive activities [1].

In our case the patient sustained the injury while running during a school recreational football match. The weight over $80 \mathrm{kgs}$ and a Body mass index of $39 \mathrm{KG} / \mathrm{M}^{2}$ and the story of previous episodes of Osgood Slater contribute actively for the fracture avulsion. Similar was reported by case series report and Javed [6], and their treatment with $4.5 \mathrm{~mm}$ partial threaded cancellous screws for the tibia tuberosity Apophysis and lateral plateau fracture. The arthrotomy was avoided in order to protect the articular space, prevent infection and scars that can limit the range of motion [7].

In our case the functional recovery at 6 months after surgery is similar as described by Pretell Mazzini, with $97 \%$ of success in sistematic review of the bibliography [8].

In our patient no complications were detected, but in the literature there are some described on the initial presentation as compartment syndrome and after treatment the presence of genu recurvatum [9], anterior knee pain, physis arrestement and very infrecuently refractures [10].

\section{Conclusion}

The avulsion fracture of the ATT is a complex and infrequent lesion, should be suspected in patients around 15 years with sudden pain on the knee, sometimes xrays are not enough to identify lesion and extension of damage. Surgical treatment is a safe option, with lower complication rate, and excellent functional and clinical results.

\section{Author Declarations}

The work was done at Clinica San Rafael, Cadiz, Cadiz, España.

No source of financial support was received.

The authors have no conflicts of interest related to the actual article.

\section{References}

1. Bolesta MJ, Fitch RD (1986) Tibial tubercle avulsions. J PediatrOrtho 6: 186-192.

2. Pandya NK, Edmonds EW, Roocroft JH, et al. (2012) Tibial tubercle fractures: Complications, classification, and the need for intra-articular assessment. Journal of Pediatric Orthopedics 32: 749-759.

3. Jakoi A, Freidl M, Javandel M, et al. (2012) Tibial tubercle avulsion fractures in adolescent basketball players Orthopedics 35: 692-696.

4. Brey JM, Conoley J, Canale ST, et al. (2012) Tibial tuberosity fractures in adolescents: Is a posterior metaphyseal fracture component a predictor of complications?. Journal of Pediatric Orthopedics 32: 561-566.

5. Ogden JA, Tross RB, Murphy MJ, et al. (1980) Fractures of the tibial tuberosity in adolescents. J Bone Joint Surg Am; 62: 205-215.

6. Javed S, Barkatali B, Siddiqui M, et al. (2013) combined avulsion fracture of the tibial tuberosity and lateral tibial plateau in an adolescent: Case report. Malaysian Orthopeadic Journal 7: 82-84. 

$4(2): 55-58$

7. Chakraverty JK, Weaver MJ, Smith RM, et al. (2009) Surgical management of tibial tubercle fractures in association with tibial plateau fractures fixed by direct wiring to a locking plate. Journal of Orthopaedic Trauma 23: 221-225.

8. Pretell-Mazzini J, Kelly DM, Sawyer JR, et al. (2016) Outcomes and complications of tibial tubercle fractures in pediatric pa- tients: A systematic review of the literature. J Pediatr Orthop 36: 440-446.

9. Nathan ST, Parikh SN (2013) Genu recurvatum after tibial tuberosity fracture. Case Rep Orthop 2013: 952978.

10. Weinlein J, Schmidt A (2010) Acute compartment syndrome in tibial plateau fractures-beware!. J Knee Surg 23: 9-16.

DOI: $10.36959 / 765 / 398$

Copyright: (C) 2020 D Godoy-Monzon, et al. This is an open-access article distributed under the terms of the Creative Commons Attribution License, which permits unrestricted use, distribution, and reproduction in any medium, provided the original author and source are credited. 